\section{Growing time lag threatens Nobels}

The time lag between reporting a scientific discovery worthy of a Nobel prize and the awarding of the medal has increased, with waits of more than 20 years becoming common. If this trend continues, some candidates might not live long enough to attend their Nobel ceremonies.

Before 1940, Nobels were awarded more than 20 years after the original discovery for only about $11 \%$ of physics, $15 \%$ of chemistry and $24 \%$ of physiology or medicine prizes, respectively. Since 1985, however, such lengthy delays have featured in $60 \%, 52 \%$ and $45 \%$ of these awards, respectively.

The increasing average interval between reporting discoveries and their formal recognition can be fitted to an exponential curve (see 'The long road to Sweden'), with data points scattered about the mean value.

As this average interval becomes longer, so the average age at which laureates are awarded the prize goes up. By the end of this century, the prizewinners' predicted average age for receiving the award is likely to exceed his or her projected life expectancy (data not shown). Given that the Nobel prize cannot be awarded posthumously, this lag threatens to undermine science's most venerable institution.

\section{Santo Fortunato* Aalto}

University, Finland. santo.fortunato@gmail.com ${ }^{\star}$ On behalf of 6 co-authors; see go.nature.com/cmmxa5 for full list.

\section{Livestock: tackle demand and yields}

Among many otherwise laudable suggestions, Mark Eisler and colleagues propose limiting feedstuffs for livestock to fibrous fodder, such as grass and silage (see Nature 507, 32-34; 2014). However, we believe that any attempt to meet the rapid growth

\title{
THE LONG ROAD TO SWEDEN
}

Scientists who publish prizewinning discoveries are, on average, waiting longer for a Nobel than ever before.

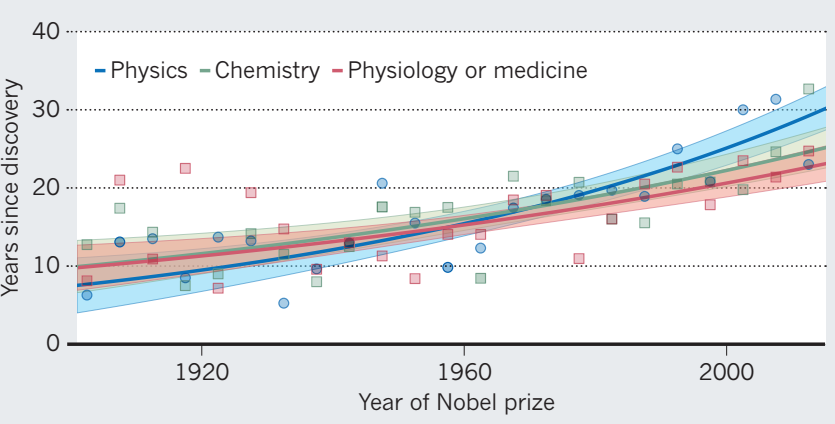

Data points are 5-year-averaged waits; shading around lines shows confidence limits.

in world demand for meat and dairy products by focusing on ruminant grazing systems would be damaging for biodiversity and for the global climate.

Although ruminants convert grass and silage into animal protein, they do so inefficiently; they therefore require much more land to produce a given amount of meat or milk than ruminants fed on diets that include grain. Growing enough fodder to satisfy demand would require the largescale expansion of grazing lands (see go.nature.com/7mf63y) - a leading cause of biodiversity loss, tropical deforestation and carbon dioxide emissions.

The environmental impacts of meat and dairy production should instead be addressed by stringent efforts to decrease consumption, halt the expansion of grazing, and increase yields on land that is already used for livestock. Promoting extensive grazing without tackling demand would do more harm than good.

Erasmus K. H. J. zu Ermgassen, David R. Williams, Andrew Balmford University of Cambridge, UK. ekhjz2@cam.ac.uk

\section{Livestock: limit red meat consumption}

Mark Eisler and co-authors advocate eating only 300 grams of red meat a week (roughly the volume of three decks of playing cards) as a step towards producing sustainable livestock (Nature 507, 32-34; 2014). That amount corresponds to $3.5-7 \%$ of a 2,000-calorie-a-day diet, depending on the cut and type of meat. Such a move would also make for a more equitable global distribution of animal-product consumption; these products comprise around $48 \%$ of the average diet in the United States, for example (S. Bonhommeau et al. Proc. Natl Acad. Sci. USA 110, 20617-20620; 2013).

Imposing a global dietary limit of 5\% red meat as part of a $10 \%$ maximum for all animal-based products would enable more people to be fed using less land. For example, eliminating livestock and using existing agricultural lands to grow crops for direct human consumption instead of for livestock fodder could feed an extra 4 billion people (E. S. Cassidy et al. Environ. Res. Lett. 8, 034015; 2013), thereby reducing or eliminating the greenhouse-gas emissions and biodiversity loss associated with conversion of natural habitats. This would also reduce many other environmental impacts of agriculture that relate to the use of water, fertilizer and fossil fuels. Brian Machovina, Kenneth J. Feeley Florida International University, Miami; and The Fairchild Tropical Botanic Garden, Coral Gables, Florida, USA. brianmachovina@gmail.com

\section{Zoo visits boost biodiversity literacy}

Zoos and aquaria worldwide attract more than 700 million visits every year. They are therefore well placed to make more people aware of the importance of biodiversity a prime target of the United Nations Strategic Plan for Biodiversity 2011-20.

We surveyed approximately 6,000 visitors to 30 zoos and aquaria in 19 countries (see go.nature.com/vwf8yf). More respondents showed improved understanding of biodiversity after their visit (75.1\% compared with $69.8 \%$ before) and more could identify an individual action that would bolster biodiversity after their visit (58.8\% compared with 50.5\% before).

Regrettably, increased awareness does not necessarily change behaviour. The world's zoo and aquarium communities must also help to drive important behavioural and social changes to assist conservation.

Andrew Moss Chester Zoo, UK. Eric Jensen University of Warwick, Coventry, UK. Markus Gusset World Association of Zoos and Aquariums, Gland, Switzerland. markus.gusset@waza.org

\section{A protein that spells trouble}

The gene CYLD is so named because one of its mutant forms is associated with cylindromatosis, which causes skin tumours.

The CYLD protein is an enzyme; its active site in humans contains a cysteine residue at position 601 (denoted as $\mathrm{C}$ in the one-letter amino-acid code). The amino-acid sequence following this cysteine $(\mathrm{C})$ is tyrosine $(\mathrm{Y})$, leucine (L) and aspartate (D). What are the odds of that? David Boone Indiana University School of Medicine - South Bend, Indiana, USA.

daboone@iu.edu 